\title{
The cancer-testis antigen $N X F 2$ is activated by the hypomethylating agent decitabine in acute leukemia cells in vitro and in vivo
}

\author{
JIHAO ZHOU, YONGHUI LI, YUSHI YAO, LIXIN WANG, LI GAO, XIAONING GAO, XUFENG LUO, \\ JINGXIN LI, MENGMENG JIANG, MINHANG ZHOU, LILI WANG and LI YU \\ Department of Hematology, Chinese People's Liberation Army General Hospital, Beijing 100853, P.R. China
}

Received April 2, 2013; Accepted August 8, 2013

DOI: $10.3892 / \mathrm{mmr} .2013 .1659$

\begin{abstract}
Cancer-testis antigens (CTAs) are a group of tumor-associated antigens restricted to male germ cells under normal physiological conditions. CTAs are expressed in certain types of tumors and thus are a novel target for immunotherapy. Nuclear RNA export factor $2(N X F 2)$ is a CTA of which the expression pattern, regulation and clinical significance are unclear. In the present study, following treatment with a demethylating agent, decitabine, $N X F 2$ expression was detected in the majority of the NXF2-negative acute leukemia cell lines, but not in healthy donor samples. This finding was confirmed by western blot analysis. Eight primary acute leukemia bone marrow samples were treated with decitabine in vitro, and results showed that NXF2 expression was significantly upregulated. In another nine acute myeloid leukemia or myelodysplastic syndrome patients, it was noted that the expression of $N X F 2$ was upregulated in all patients following the first cycle of decitabine, which suggested that $N X F 2$ was activated by decitabine treatment in vivo. Furthermore, $N X F 2$ expression in acute leukemia cells was demonstrated to be regulated by $\mathrm{CpG}$ island hypermethylation. To the best of our knowledge, this is the first study to demonstrate that NXF2 is activated by demethylation in acute leukemia cells in vitro and in vivo. NXF2 may therefore serve as a novel target for immunotherapy against acute leukemia.
\end{abstract}

\section{Introduction}

Cancer-testis antigens (CTAs) are a group of antigens that are exclusively expressed in germline cells, such as testis and placental cells under normal physiological conditions. CTAs

Correspondence to: Professor Li Yu, Department of Hematology, Chinese People's Liberation Army General Hospital, 28 Fuxing Road, Beijing 100853, P.R. China

E-mail: chunhuiliyu@yahoo.com

Key words: cancer-testis antigens, nuclear RNA export factor 2, decitabine, methylation, acute leukemia are also expressed in numerous human tumor cells of various histological origins (1). The first CTA identified in 1991 is termed melanoma-associated antigen 1 (MAGE-Al) (2). In 1994, Weber et al (3) demonstrated that decitabine, a demethylation agent, upregulates $M A G E-A l$ expression in melanoma cell lines. In 1996, the activation of $M A G E-A 1$ in tumor cells was correlated with genome-wide demethylation (4). Subsequent to this, more CTAs were identified, including PRAME (5), NY-ESO-1 (6) and SSX family antigens (7). Numerous studies concerning the immunogenicity of CTAs and the asssociation between CTAs and demethylation have been conducted (8-11). For example, in acute myeloid leukemia (AML) cell lines, NY-ESO-1 was upregulated by decitabine and thus decitabine-treated AML cells become susceptible to NY-ESO-1-specific T-cell cytotoxicity (8). Those results have suggested CTA to be a potential target for tumor immunotherapy. However, the majority of studies concerning CTAs and decitabine were limited to in vitro investigations and few CTAs have been demonstrated to be activated by decitabine in vivo by clinical decitabine treatment.

The nuclear RNA export factor 2 (NXF2) human gene was first identified in spermatogonia (12). Early studies on $N X F 2$ were focused on its function as an mRNA exporter (13) and its involvement in male infertility (14-16). NXF2 has been found to be positive in $1.8 \%$ of invasive ductal carcinomas of the breast (17). Dubovsky et al (18) observed its involvement in chronic lymphocytic leukemia (CLL). Following screening of 22 CLL patients, two were observed to be positive for NXF2-specific IgG antibodies. The presence of these antibodies supported the hypothesis that NXF2 exhibits high enough immunogenicity to induce tumor-specific immune responses (18). However, no studies have been conducted concerning the expression pattern, regulation mechanism and clinical significance of $N F X 2$ in acute leukemia. The aim of the current study was to investigate the expression and epigenetic regulation mechanism of $N X F 2$ in acute leukemia cells, in vitro and in vivo.

\section{Materials and methods}

Cell lines and patient samples. Bone marrow and peripheral blood samples were collected from healthy donors and 
leukemia patients in the Hematology Department of the Chinese People's Liberation Army General Hospital, (Beijing, China). Samples of testis were provided by the laboratory of the Urology Department, Peking University Third Hospital (Beijing, China). Written informed consent was obtained from all donors and patients. All experiments were approved by the ethics committee of the Chinese People's Liberation Army General Hospital. Raji, Z-138, Hut-78, Jurkat, Molt-4, Kasumi-1, NB4, THP-1, U937 and K562 acute leukemia cell lines were obtained from the cell culture center of Peking Union Medical College (Beijing, China). Primary cells were separated from bone marrow or peripheral blood samples using the Ficoll-Paque method (19). Cell lines and primary acute leukemia cells were maintained in RPMI-1640 supplemented with $10 \%$ fetal calf serum, $1 \%$ penicillin/streptomycin and $1 \%$ glutamine. Cultures were maintained in a $5 \%$ $\mathrm{CO}_{2}$-humidified incubator at $37^{\circ} \mathrm{C}$. Decitabine (5-aza-2'-deoxycytidine, Dacogen, DAC) was purchased from Xi'an Jansson Pharmaceutical, Ltd. (Xi'an, China). For demethylation treatment, decitabine was added to the in vitro culture system at a concentration of $1 \mu \mathrm{mol} / 1$ for 3 days for leukemia cell lines and $5 \mu \mathrm{mol} / 1$ for 3 days for primary leukemia samples (18). For clinical treatment, decitabine was administered alone at a dose of $20 \mathrm{mg} / \mathrm{m}^{2} /$ day for 5 consecutive days (20).

$R N A$ isolation, reverse transcription and semi-quantitative reverse transcription-polymerase chain reaction (RT-PCR). Total RNA was extracted from samples or cell lines with TRIzol reagent (Invitrogen Life Technologies, Carlsbad, CA, USA), according to the manufacturer's instructions. Total RNA was reverse transcribed to complementary DNA (cDNA) as previously described (21). Reverse transcription and semi-quantitative RT-PCR were conducted on a Veriti ${ }^{\circledR}$ Thermal Cycler (Applied Biosystems, Inc., Foster City, CA, USA). Primers used for semi-quantitative RT-PCR were: Forward: 5'-TGA AAC CCT GCA AGG AAA AC-3' and reverse: 5'-GCA CTG AGG GAG TCC ACA AT-3' for $N X F 2$; and forward: 3'-GAG TCA ACG GAT TTG GTC GT-5' and reverse: 3'-TTG ATT TTG GAG GGA TCT CG-5' for glyceraldehyde 3-phosphate dehydrogenase $(G A P D H)$. The $25 \mu \mathrm{l}$ PCR mixture was prepared with $12.5 \mu 12 \mathrm{X}$ GoTaq Green Master mix (Promega Corporation, Fitchburg, WI, USA), cDNA, primers and nuclease-free water. The amplification procedure was as follows: 35 cycles of denaturation for $30 \mathrm{sec}$ at $95^{\circ} \mathrm{C}$, annealing for $50 \mathrm{sec}$ at $60^{\circ} \mathrm{C}$ and extension for $50 \mathrm{sec}$ at $72^{\circ} \mathrm{C}$. PCR amplification products were analyzed on $1.5 \%$ agarose gels stained with ethidium bromide.

$q P C R$. qPCR was performed to quantify target genes in bone marrow samples using the Stratagene Mx3000P real-time qPCR system (Stratagene, La Jolla, CA, USA). Primers and probes used were: Forward: 3'-GAAGCCAGGCCAAAT GGA-5', reverse: 3'-AGTCTGGGTCAAAGCGGAGAT-5' and probe: 3'-FAM-ATGAACAAACGGTACAATGTCTCC CA-TAMRA-5' for NFX2; and forward: CATACCAGGAAA TGAGCTTGACAA, reverse: CATACCAGGAAATGAGCT TGACAA and probe: 3'-FAM-CTCCTCTGACTTCAA CAGCGACACCCA-TAMRA-5'. Each qPCR reaction was conducted in $20 \mu \mathrm{l}$ reaction volume with TaqMan universal master mix (Applied Biosystems, Inc.), $0.25 \mu \mathrm{M}$ primers and probe and 20 ng cDNA. The amplification procedure was as follows: 40 cycles of denaturation for $15 \mathrm{sec}$ at $95^{\circ} \mathrm{C}$ and annealing for $60 \mathrm{sec}$ at $60^{\circ} \mathrm{C}$. NXF2 mRNA expression was determined by $2^{-\triangle \triangle C T}$ relative to $G A P D H$.

Western blot analysis. Protein extracts from U937 and Raji cells were isolated using immunoprecipitation assay buffer (Sigma-Aldrich, St. Louis, MO, USA) and quantified to ensure equivalent protein loading. Polyacrylamide gel electrophoresis, tank-based transfer to Immobilon Hybond-C membranes (Amersham Pharmacia Biotech, Piscataway, NJ, USA) and immunodetection were performed as described (22). $\beta$-actin antibody was purchased from Abcam (Cambridge, MA, USA) and NXF2 antibody was purchased from Sigma-Aldrich. Signals were visualized using Immobilon Western Chemiluminescent horseradish peroxidase substrate (Millipore Corporation, Billerica, MA, USA) by exposure to films (Kodak, Rochester, NY, USA).

Firefly luciferase reporter constructs. Five promoter regions of the wild-type human $N X F 2$ gene were amplified from one testis sample by PCR using specific primers (Fig. 3A). Primers were designed to contain KpnI and HindIII restriction enzyme sites. Sense primers used were: 5'-CGGGGTACCAGT GTGGGCTGAGGGTTG GA-3', $-1,000$ to +28 bp for P1; 5'-CGGGGTACCGTAAGCATCCCCTGCTACACG-3', -744 to +28 bp for P2; 5'-CGGGGTACCCAGGTGCCTGTAATG CCAGCT-3', -512 to +28 bp for P3; 5'-CGGGGTACCCAG AGCGAGACGCCGTCT-3', -400 to +28 bp for P4; 5'-CGG GGTACCGGCAGGCTTATAATCAGAACACCC-3', -229 to +28 bp for P5; and the antisense primer was 5'-CCCAAG CTTCAAAGCAGTGGGGAGAGGAC-3'. The amplified promoter regions were cloned downstream of the firefly luciferase-coding region between KpnI and HindIII of a modified pGL3-control plasmid. Successful construction was confirmed by sequencing.

Transfection and luciferase assays. 293T cells were plated in 24 -well plates at $5 \times 10^{4}$ cells/well and grown overnight. Firefly luciferase reporter vector $(500 \mathrm{ng})$ containing different promoter regions of NXF2 and $10 \mathrm{ng}$ control vector pRL-TK (Promega Corporation) containing Renilla luciferase were cotransfected to $293 \mathrm{~T}$ cells in a final volume of $0.35 \mathrm{ml}$ using SuperFect (Qiagen, Hilden, German). Cells were collected $48 \mathrm{~h}$ following transfection and luciferase activity was measured using a dual-reporter luciferase assay system (Promega Corporation).

Bisulfite modification and genomic sequencing. Genomic DNA was extracted from cells using the Wizard Genomic DNA Purification kit (Promega Corporation). DNA (1 $\mu \mathrm{g})$ was modified with sodium bisulfite using the EpiTect Bisulfite kit (Qiagen). Primers for bisulfite-sequencing analysis were designed by MethPrimer software (San Francisco, CA, USA) (23) using the bisulfite-treated DNA as a template (Forward: 5'-GAGTTTTTAATTGTTTGTGTTGAG-3' and reverse: 5'-GGTAGAGGTTGTATGAGATGGG-3'). PCR products were gel-purified and cloned into a pGEM-T vector (Promega Corporation). The inserted PCR fragments of individual clones were sequenced using an ABI PRISM DNA sequencer (Applied Biosystems, Inc.). 
A

NBM1 NBM2 NPB1 NPB2 Testis1 Testis2

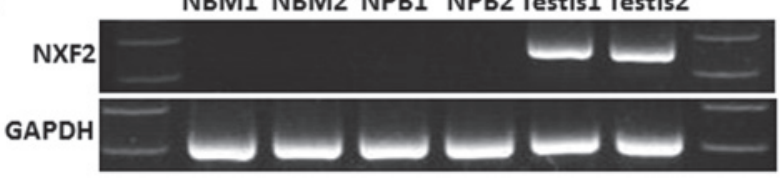

B

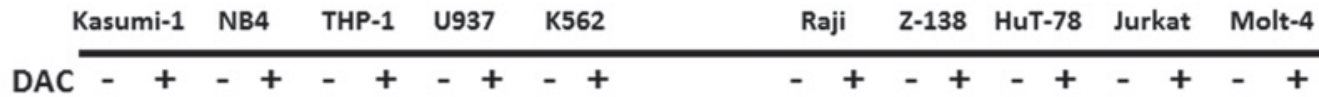

NXF2
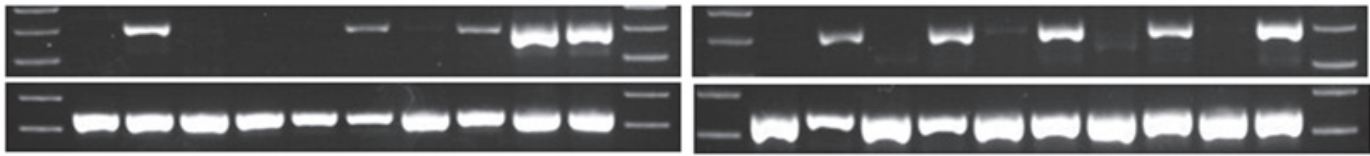

C

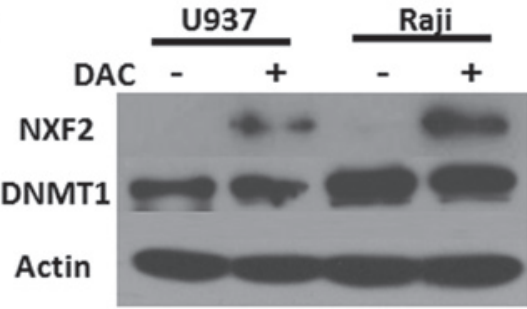

D

In Raji cells

\begin{tabular}{|c|c|c|c|c|c|c|c|c|c|c|c|c|c|}
\hline DAC dos & $\mathrm{e}(\mu \mathrm{M})$ & 0 & 0.5 & 1 & 2 & 3 & Time (days) & 0 & 1 & 7 & 14 & 21 & 28 \\
\hline NXF2 & - & & - & - & 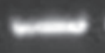 & 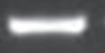 & -5 & & 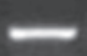 & 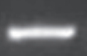 & - & - & - \\
\hline
\end{tabular}

Figure 1. Decitabine activated $N X F 2$ expression in acute leukemia cell lines in vitro. (A) RT-PCR showed that $N X F 2$ was originally expressed only in testis and not in bone marrow or peripheral blood samples from healthy donors. (B) Acute leukemia cell lines, including 5 acute myeloid leukemia cell lines (Kasumi-1, NB4, THP-1, U937 and K562) and 5 acute lymphocytic leukemia cell lines (Raji, Z-138, HuT-78, Jurkat and Molt-4) were screened for NXF2 expression prior to and following $1 \mu \mathrm{M}$ decitabine treatment for 3 days in vitro. NXF2 expression was positive in K562 cells and was activated in the majority of other acute leukemia cell lines except NB4 following decitabine treatment. (C) In Raji and U937 cells, upregulation of NXF2 expression following decitabine treatment was confirmed by western blot analysis. $\beta$-actin was used as the positive control. (D) In Raji cells, $N X F 2$ activation was decitabine dose-dependent and its expression lasted $\geq 28$ days following the cessation of decitabine treatment. DAC, decitabine-treated cells; NFX2, nuclear RNA export factor 2.

\section{Results}

Activation of NXF2 expression following decitabine treatment in acute leukemia cell lines. NXF2 expression was screened in two normal bone marrow (NBM) samples, two normal peripheral blood samples and two normal testis samples. The results showed that $N X F 2$ was only positively expressed in the testis samples (Fig. 1A). NXF2 expression was screened in 10 acute leukemia cell lines, including five AML cell lines (Kasumi-1, NB4, THP-1, U937 and K562 cell lines; K562 cells are cells of the blastic transformation of chronic myeloid leukemia) and five acute lymphocytic leukemia (ALL) cell lines (Raji, Z-138, HuT-78, Jurkat and Molt-4), prior to and following decitabine treatment. The results showed that only K562 cells expressed NXF2 originally. However, following decitabine treatment, eight of the remaining nine acute leukemia cell lines demonstrated activation of $N X F 2$ expression, with the exception of NB4 cells (Fig. 1B). This upregulation was confirmed in one AML cell line (U937) and one ALL cell line (Raji) by western blot analysis (Fig. 1C). Raji cells were then analyzed for the effect of different doses of decitabine on the activa- tion of $N X F 2$. The results showed that $N X F 2$ activation was dose-dependent. Following treatment with $1 \mu \mathrm{M}$ decitabine for 3 days, it was noted that $N X F 2$ remained positive 28 days subsequent to the cessation of decitabine treatment (Fig. 1D).

Activation of NXF2 expression following decitabine treatment in primary acute leukemia cells in vitro and in vivo. Primary cells from 11 bone marrow samples, including four AML patients, four ALL patients and three healthy donors were collected. The primary cells were treated with $5 \mu \mathrm{M}$ decitabine for 3 days in vitro. Relative $N X F 2$ expression (Fig. 2A) was low in the majority of the samples. Following decitabine treatment, NXF2 mRNA expression in all acute leukemia samples was significantly upregulated. However, this upregulation was not observed in healthy donor samples. The results suggested that decitabine treatment activated $N X F 2$ expression in primary acute leukemia cells in vitro.

In addition, another nine patients with AML or myelodysplastic syndrome, who received decitabine treatment clinically were selected. The samples were collected prior to and following the first cycle of decitabine treatment. The 


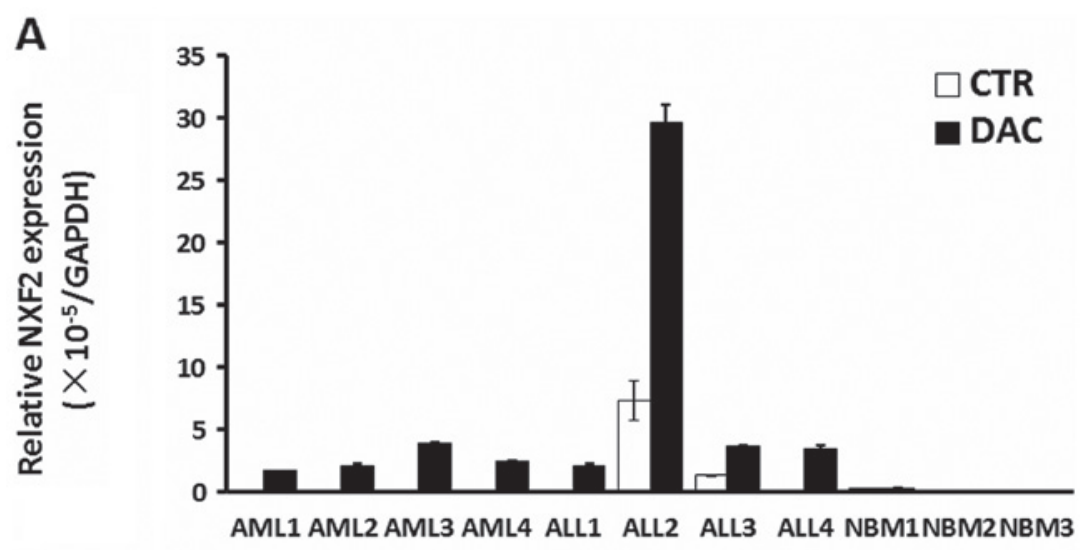

B

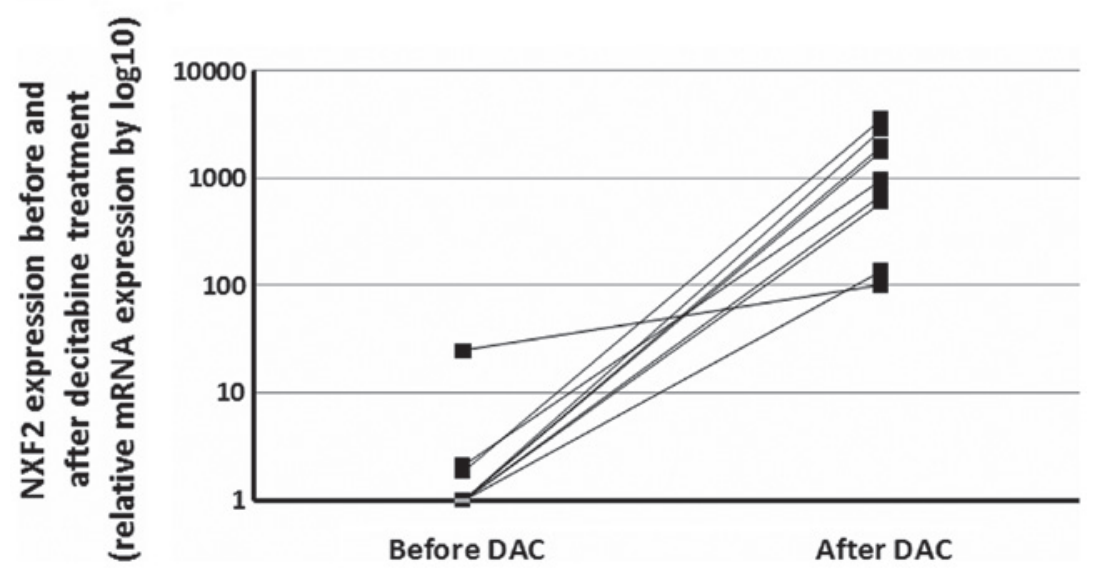

Figure 2. Decitabine activated NXF2 expression in primary acute leukemia cells in vitro and in vivo. (A) Bone marrow samples from four AML patients, four acute lymphocytic leukemia patients and three healthy donors were collected and screened for NXF2 expression before and after decitabine treatment in vitro. NXF2 was activated in the majority of leukemia samples; however, no or only marginal upregulation was observed in healthy donor samples by qPCR. (B) NXF2 expression levels were analyzed in samples from nine AML or myelodysplastic syndrome patients before and after their first decitabine treatment. Patient characteristics are listed in Table I. Decitabine treatment was shown to activate $N X F 2$ expression in acute leukemia cells in vivo. Values are presented as the mean \pm SD of triplicates. NFX2, nuclear RNA export factor 2; AML, acute myeloid leukemia; ALL, acute lymphocytic leukemia; CTR, control cells; DAC, decitabine-treated cells.

characteristics of these patients are listed in Table I. Samples were obtained from the bone marrow, with the exception of patient 6 , which was a peripheral blood sample as the patient had hyperleukocytosis.

As the nine patients did not respond to the first cycle of decitabine, leukemia cells were observed in all of the samples. qPCR results showed that $N X F 2$ expression was upregulated to varying degrees in all nine patients following decitabine treatment (Fig. 2B). This result suggests that decitabine treatment activated NXF2 expression in primary acute leukemia cells in vivo.

NXF2 expression correlates with $C p G$ island hypomethylation in its promoter region. There was a typical $\mathrm{CpG}$ island located in the NXF2 promoter region spanning 282 bp and containing $14 \mathrm{CpG}$ sites (Fig. 3A and C). By luciferase reporter construction, it was demonstrated that the promoter region containing the $\mathrm{CpG}$ island was essential for $N X F 2$ expression (Fig. 3B). The methylation status of this $\mathrm{CpG}$ island in two NBM samples without $N X F 2$ expression in one testis sample and in K562 cells with NXF2 expression was detected. The $\mathrm{CpG}$ island was densely-methylated in the two NBM samples (>90\%), but only partially methylated in the testis sample and in the K562 cells (Fig. 3D). Raji and U937 cell lines were originally NXF2-negative and were analyzed for the methylation status of the $\mathrm{CpG}$ island prior to and following decitabine treatment. The methylation level of the $\mathrm{CpG}$ island decreased following decitabine treatment, concurrent with NXF2 activation (Fig. 3E). These results suggest that NXF2 expression was silenced by $\mathrm{CpG}$ island hypermethylation; thus, decitabine activated NXF2 expression by the demethylation mechanism.

\section{Discussion}

$N X F 2$ is a CTA gene, however, there is limited information available concerning its expression pattern and the mechanism of $N X F 2$ regulation. The present study showed that $N X F 2$ expression was activated by a demethylating agent, decitabine, in acute leukemia cell lines and primary acute leukemia samples in vitro and in vivo. This study also showed that NXF2 expression is regulated by $\mathrm{CpG}$ island hypermethylation in its promoter region. To the best of our knowledge, this is the first study to demonstrate the mechanism of $N X F 2$ regulation in acute leukemia cells.

Currently, certain CTAs have been demonstrated to be potential targets for immunotherapy against cancer due 
Table I. Patient characteristics.

\begin{tabular}{|c|c|c|c|c|c|c|c|c|}
\hline Patient & $\begin{array}{c}\text { Age } \\
\text { (years) }\end{array}$ & Gender & Chromosome & $\begin{array}{c}\text { Gene } \\
\text { abnormalities }\end{array}$ & Diagnosis & Response & $\begin{array}{l}\text { DAC } \\
\text { cycles }\end{array}$ & Prognosis \\
\hline 1 & 61 & M & $46, X Y$ & $M L L-P T D(+)$ & MDS-RAEB & Failure & 3 & $\begin{array}{l}\text { Progressed to AML } \\
\text { after } 3 \text { cycles }\end{array}$ \\
\hline 2 & 75 & M & $\begin{array}{c}\text { 46,XY,12p- } \\
\text { inc[10]/, hypo- } \\
\text { diploid(43-45) }\end{array}$ & $\begin{array}{c}\text { NUP98/ } \\
\text { HOXA9(+) }\end{array}$ & $\begin{array}{l}\text { AML (MDS } \\
\text { transformed) }\end{array}$ & SD & 8 & Still in DAC maintenance \\
\hline 3 & 38 & M & $46, X Y$ & - & $\begin{array}{l}\text { AML (MDS } \\
\text { transformed) }\end{array}$ & SD & 5 & $\begin{array}{l}\text { Quit DAC treatment } \\
\text { after the } 5 \text { th cycle }\end{array}$ \\
\hline 4 & 62 & $\mathrm{~F}$ & $46, X X$ & - & $\begin{array}{l}\text { AML (MDS } \\
\text { transformed) }\end{array}$ & PD & 3 & $\begin{array}{l}\text { Quit DAC treatment } \\
\text { after the } 3 \text { rd cycle }\end{array}$ \\
\hline 5 & 53 & $\mathrm{~F}$ & $46, X X$ & $\begin{array}{c}\text { GIT2/ } \\
P D G F R B(+)\end{array}$ & $\begin{array}{l}\text { AML (CMML } \\
\text { transformed) }\end{array}$ & PD & 3 & $\begin{array}{l}\text { This patient received TKI } \\
\text { treatment first. DAC was } \\
\text { added in combination with } \\
\text { TKI when her CMML } \\
\text { progressed to AML. She quit } \\
\text { DAC treatment after the 3rd } \\
\text { cycle and received allo-HSCT }\end{array}$ \\
\hline 6 & 49 & M & - & - & AML-M6 & SD & 7 & $\begin{array}{l}\text { Quit DAC treatment and } \\
\text { received allo-HSCT after } \\
\text { the } 7 \text { th cycle }\end{array}$ \\
\hline 7 & 59 & $\mathrm{~F}$ & $46, X Y$ & - & $\begin{array}{l}\text { AML (MDS } \\
\text { transformed) }\end{array}$ & $\mathrm{CR}$ & 14 & $\begin{array}{l}\text { CR after the } 7 \text { th cycle, but } \\
\text { relapsed after the } 14 \text { th cycle, } \\
\text { quit DAC treatment after } \\
\text { relapse }\end{array}$ \\
\hline 8 & 64 & M & $46, X Y$ & $\begin{array}{l}\text { P15 hyper- } \\
\text { methylated }\end{array}$ & $\begin{array}{l}\text { AML (MDS } \\
\text { transformed) }\end{array}$ & $\mathrm{CR}$ & 12 & $\begin{array}{l}\text { CR after the } 5 \text { th cycle, but } \\
\text { relapsed after the } 10 \text { th cycle, } \\
\text { quit DAC treatment after } \\
\text { relapse. }\end{array}$ \\
\hline 9 & 82 & $\mathrm{~F}$ & $46, X X$ & - & $\begin{array}{l}\text { AML (MDS } \\
\text { transformed) }\end{array}$ & PR & 10 & $\begin{array}{l}\text { PR after the } 4 \text { th cycle, but } \\
\text { turned to AML after the } 7 \text { th } \\
\text { cycle, another } 3 \text { cycles of } \\
\text { DAC after progression } \\
\text { did not work }\end{array}$ \\
\hline
\end{tabular}

All samples were bone marrow samples except for patient 6 . The samples collected from patient 6 were peripheral blood samples because the patient had hyperleukocytosis. M, male; F, female DAC, decitabine ; MDS, myelodysplastic syndrome; RAEB, refractory anemia with excess blasts; AML, acute myeloid leukemia; CR, complete remission; PR, partial remission; SD, stable disease; PD, progressive disease; CMML, chronic myelomonocytic leukemia; TKI, tyrosine-kinase inhibitor; allo-HSCT, allogeneic hematopoietic stem cell transplantation; AML-M6, acute erythroid leukemia.

to their tumor specificity and strong immunogenicity. For example, Hunder et al (9) expanded autologous CD4 ${ }^{+}$T-cell clones specific for NY-ESO-1 (a CTA). Specific T cells were infused into a patient with refractory metastatic melanoma and a durable clinical remission was observed. In another study, Quintarelli et al (24) showed that cytotoxic T lymphocytes specific for PRAME, another type of CTA, target leukemic and leukemic-precursor cells. It was also demonstrated that NXF2 exhibits a high enough level of immunogenicity to induce immune responses in CLL patients (18). However, the application of CTA-specific immunotherapy is limited due to a relatively low expression in acute leukemia. It was suggested that this limitation was able to be overcome by demethylation treatment. Yan et al (25) demonstrated that, following demethylation treatment, the expression of PRAME in the ALL cell line (Raji cells) was upregulated. These Raji cells with greater PRAME expression showed increased sensitivity to killing by formerly low avidity PRAME-specific T-cell clones. However, the majority of similar studies are performed in vitro and few studies have observed that CTAs were activated in malignant 

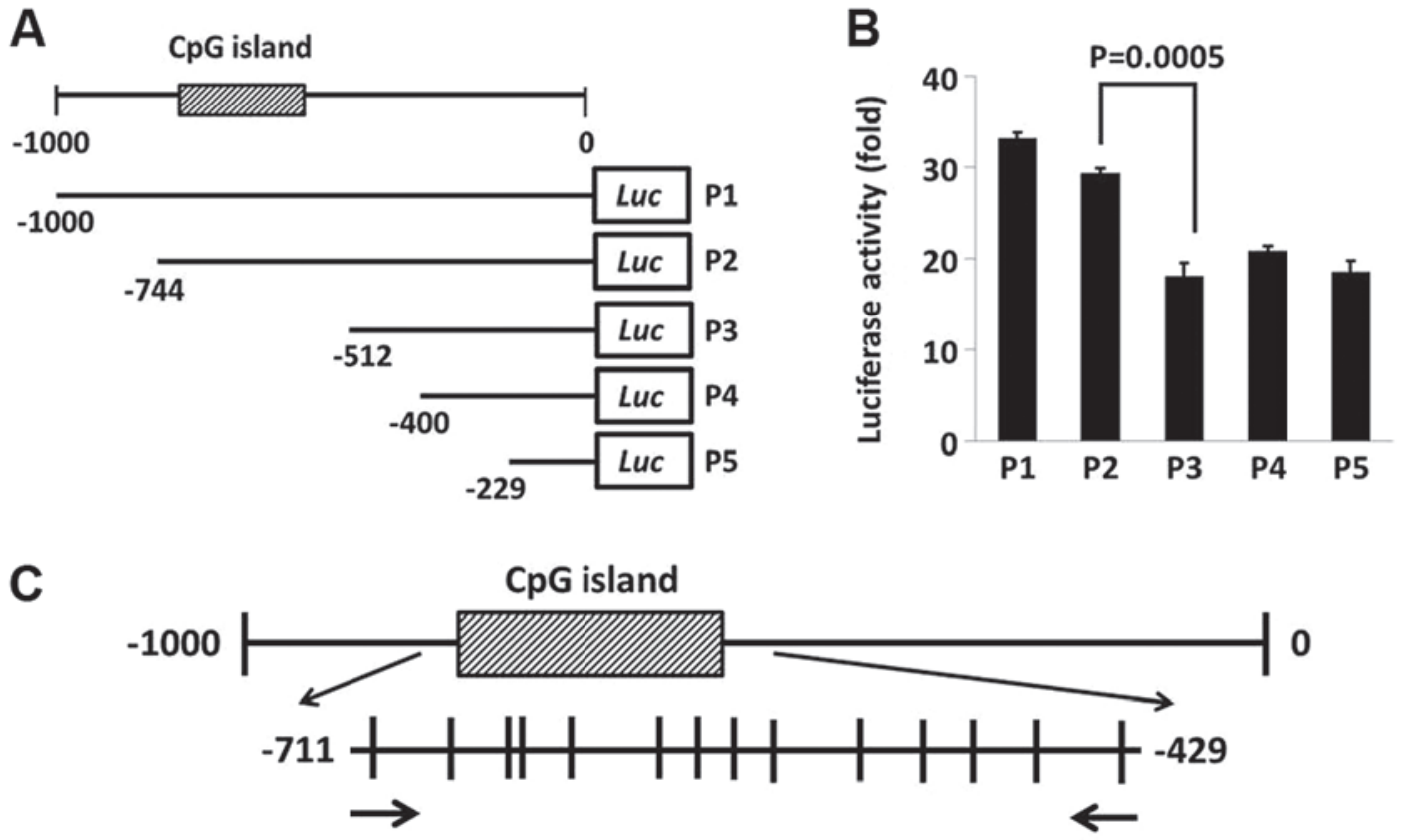

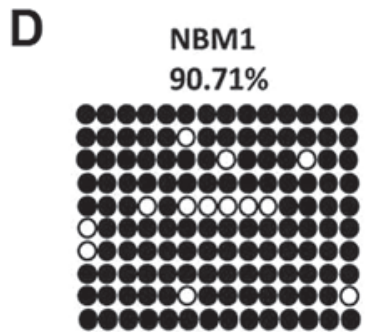

Testis

$47.86 \%$

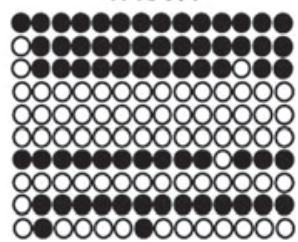

NBM2

92.86\%

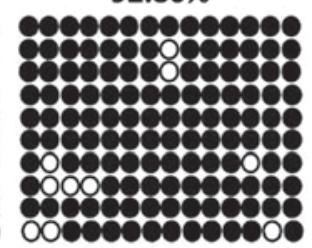

K562

$34.29 \%$

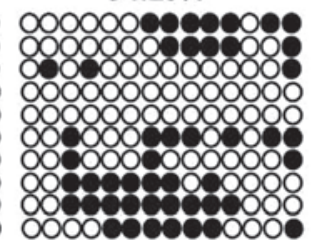

E

CTR U937

$87.86 \%$

CTR Raji

93.57\%

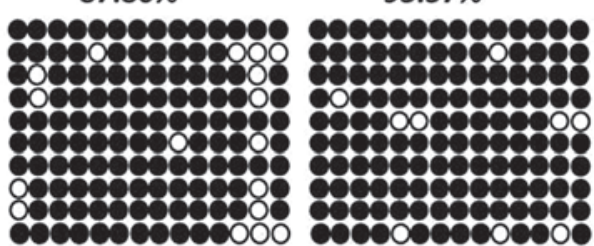

DAC U937

DAC Raji

$55.00 \%$

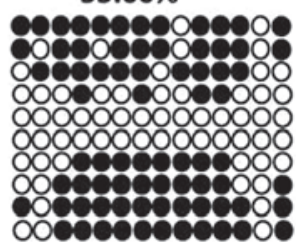

$61.43 \%$

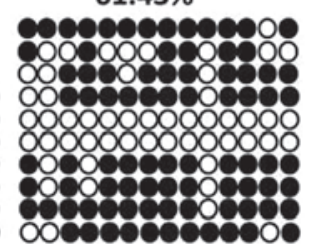

Figure 3. Activation of NXF2 was associated with $\mathrm{CpG}$ island demethylation in its promoter region. (A) Firefly luciferase reporter constructs. A typical CpG island located in the promoter region of the $N X F 2$ gene. (B) Firefly luciferase assay indicated that the promoter region containing the $\mathrm{CpG}$ island is essential for NXF2 expression. (C) It was demonstrated that there are $14 \mathrm{CpG}$ sites in the $\mathrm{CpG}$ island. (D) The $\mathrm{CpG}$ island was densely methylated in two normal bone marrow samples without $N X F 2$ expression; however, less methylated in testis sample and in K562 cells with $N X F 2$ expression. (E) The CpG island was densely methylated in Raji and U937 cells without NXF2 expression. Following decitabine treatment, the methylation level decreased in accordance with $N X F 2$ activation. Black dots indicate methylated $\mathrm{CpG}$ sites and white dots indicate unmethylated CpG sites. NFX2, nuclear RNA export factor; CTR, control cells; DAC, decitabine-treated cells.

cells in vivo by clinical decitabine treatment. In the present study it was demonstrated that $N X F 2$ was activated in acute leukemia cells not only in vitro, but also in vivo by clinical decitabine treatment. It was hypothesized that NXF2 served as a novel target for immunotherapy against acute leukemia following clinical demethylation treatment. However, as no epitope sequence of NXF2 has yet been identified, it was difficult to determine the details of NXF2-specific immune responses following decitabine treatment. Thus, future studies are required to investigate the epitope of NXF2.

In conclusion, to the best of our knowledge, this was the first study to demonstrate that NXF2 is activated by decitabine in acute leukemia cells in vitro and in vivo; this activation was due to demethylation of the $\mathrm{CpG}$ island in the $N X F 2$ promoter region. According to these results, it was hypothesized that NXF2 may serve as a novel clinical target for immunotherapy against acute leukemia.

\section{Acknowledgements}

This study was supported by grants from the National Basic Research Program of China (grant no. 2005CB522400); the National Natural Science Foundation of China (grant nos. 90919044, 30971297 and 81000221); the Capital Medical Development Scientific Research Fund (grant no. 2007-2040); the National Public Health Grand Research 
Foundation (grant no. 201202017); and the capital of the Public Health Project (grant no. Z111107067311070).

\section{References}

1. Fratta E, Coral S, Covre A, et al: The biology of cancer testis antigens: putative function, regulation and therapeutic potential. Mol Oncol 5: 164-182, 2011.

2. van der Bruggen $\mathrm{P}$, Traversari $\mathrm{C}$, Chomez $\mathrm{P}$, et al: A gene encoding an antigen recognized by cytolytic $\mathrm{T}$ lymphocytes on a human melanoma. Science 254: 1643-1647, 1991.

3. Weber J, Salgaller M, Samid D, et al: Expression of the MAGE-1 tumor antigen is up-regulated by the demethylating agent 5-aza-2'-deoxycytidine. Cancer Res 54: 1766-1771, 1994.

4. De Smet C, De Backer O, Faraoni I, Lurquin C, Brasseur F and Boon T: The activation of human gene MAGE-1 in tumor cells is correlated with genome-wide demethylation. Proc Natl Acad Sci USA 93: 7149-7153, 1996.

5. van Baren N, Chambost H, Ferrant A, et al: PRAME, a gene encoding an antigen recognized on a human melanoma by cytolytic $\mathrm{T}$ cells, is expressed in acute leukaemia cells Br J Haematol 102: 1376-1379, 1998.

6. Chen YT, Boyer AD, Viars CS, Tsang S, Old LJ and Arden KC: Genomic cloning and localization of CTAG, a gene encoding an autoimmunogenic cancer-testis antigen NY-ESO-1, to human chromosome Xq28. Cytogenet Cell Genet 79: 237-240, 1997.

7. Gure AO, Türeci O, Sahin U, et al: SSX: a multigene family with several members transcribed in normal testis and human cancer. Int J Cancer 72: 965-971, 1997.

8. Almstedt M, Blagitko-Dorfs N, Duque-Afonso J, et al: The DNA demethylating agent 5-aza-2'-deoxycytidine induces expression of NY-ESO-1 and other cancer/testis antigens in myeloid leukemia cells. Leuk Res 34: 899-905, 2010.

9. Hunder NN, Wallen H, Cao J, et al: Treatment of metastatic melanoma with autologous $\mathrm{CD}^{+}{ }^{+} \mathrm{T}$ cells against NY-ESO-1. N Engl J Med 358: 2698-2703, 2008.

10. Fradet Y, Picard V, Bergeron A and LaRue H: Cancer-testis antigen expression in bladder cancer. Prog Urol 15 (Suppl 1): $1303-1313,2005$.

11. Calabrò L, Fonsatti E, Altomonte M, et al: Methylation-regulated expression of cancer testis antigens in primary effusion lymphoma: immunotherapeutic implications. J Cell Physiol 202: 474-477, 2005.

12. Wang PJ, McCarrey JR, Yang F and Page DC: An abundance of X-linked genes expressed in spermatogonia. Nat Genet 27: 422-426, 2001
13. Takano K, Miki T, Katahira J and Yoneda Y: NXF2 is involved in cytoplasmic mRNA dynamics through interactions with motor proteins. Nucleic Acids Res 35: 2513-2521, 2007.

14. Chen CP, Su YN, Lin HH, et al: De novo duplication of Xq22.1 $\rightarrow$ q24 with a disruption of the NXF gene cluster in a mentally retarded woman with short stature and premature ovarian failure. Taiwan J Obstet Gynecol 50: 339-344, 2011.

15. Pan J, Eckardt S, Leu NA, et al: Inactivation of Nxf2 causes defects in male meiosis and age-dependent depletion of spermatogonia. Dev Biol 330: 167-174, 2009.

16. Stouffs K, Tournaye H, Van der Elst J, Liebaers I and Lissens W: Is there a role for the nuclear export factor 2 gene in male infertility? Fertil Steril 90: 1787-1791, 2008.

17. Chen YT, Ross DS, Chiu R, et al: Multiple cancer/testis antigens are preferentially expressed in hormone-receptor negative and high-grade breast cancers. PLoS One 6: e17876, 2011.

18. Dubovsky JA, McNeel DG, Powers JJ, Gordon J, Sotomayor EM and Pinilla-Ibarz JA: Treatment of chronic lymphocytic leukemia with a hypomethylating agent induces expression of NXF2, an immunogenic cancer testis antigen. Clin Cancer Res 15: 3406-3415, 2009.

19. Jaatinen $T$ and Laine J: Isolation of mononuclear cells from human cord blood by Ficoll-Paque density gradient. Curr Protoc Stem Cell Biol Chapter 2: Unit 2A.1, 2007.

20. Lübbert M, Ruter BH, Claus R, et al: A multicenter phase II trial of decitabine as first-line treatment for older patients with acute myeloid leukemia judged unfit for induction chemotherapy. Haematologica 97: 393-401, 2012.

21. van Dongen JJ, Macintyre EA, Gabert JA, et al: Standardized RT-PCR analysis of fusion gene transcripts from chromosome aberrations in acute leukemia for detection of minimal residual disease. Report of the BIOMED-1 Concerted Action: investigation of minimal residual disease in acute leukemia. Leukemia 13: 1901-1928, 1999.

22. Li CS, Chen C, Zheng P and Liu Y: Transgenic expression of P1A induced thymic tumor: a role for onco-fetal antigens in tumorigenesis. PLoS One 5: e13439, 2010.

23. Li LC and Dahiya R: MethPrimer: designing primers for methylation PCRs. Bioinformatics 18: 1427-1431, 2002.

24. Quintarelli C, Dotti G, Hasan ST, et al: High-avidity cytotoxic T lymphocytes specific for a new PRAME-derived peptide can target leukemic and leukemic-precursor cells. Blood 117: 3353-3362, 2011

25. Yan M, Himoudi N, Basu BP, et al: Increased PRAME antigen-specific killing of malignant cell lines by low avidity CTL clones, following treatment with 5-aza-2'-deoxycytidine. Cancer Immunol Immunother 60: 1243-1255, 2011. 